\title{
Lipoprotein Metabolism, Insulin Resistance, and Adipocytokine Levels in Japanese Female Adolescents With a Normal Body Mass Index and High Body Fat Mass
}

\author{
Noriaki Kishimoto, MD; Koichi Okita, MD*; Shingo Takada*; Ichiro Sakuma, MD**; \\ Yasuaki Saijo, $\mathrm{MD}^{\dagger}$; Hitoshi Chiba, $\mathrm{MD}^{\dagger \dagger}$; Kojiro Ishii, $\mathrm{PhD}{ }^{\ddagger}$; \\ Reiko Kishi, MD津; Hiroyuki Tsutsui, MD
}

\begin{abstract}
Background: The prevalence of obesity is gradually increasing in Japan, but in women aged in their $20 \mathrm{~s}$ to $50 \mathrm{~s}$ it has been disproportionately decreasing. However, the exact body composition of this subset of the population has not been elucidated.

Methods and Results: Body composition was determined using whole-body dual energy X-ray absorptiometry and metabolic parameters in 157 Japanese female university students (21.1 1.9 years); 31 women had a normal body mass index (BMI), but an increased body fat mass (BFM). Only the 31 had significantly higher low-density lipoprotein-cholesterol levels $(90.5 \mathrm{vs} 99.0 \mathrm{mg} / \mathrm{dl}, \mathrm{P}<0.01)$ and leptin concentration $(7.0 \mathrm{vs} 4.6 \mathrm{ng} / \mathrm{ml}, \mathrm{P}<0.05)$ and lower high-density lipoprotein-cholesterol $(80.4 \pm 15.1$ vs $73.5 \pm 14.5 \mathrm{mg} / \mathrm{dl}, \mathrm{P}<0.01)$ than females with normal BMI and normal BFM.

Conclusions: A considerable number of young Japanese women with a normal BMI have excess BFM and relatively higher lipid and leptin levels. These findings may provide an important basis for future epidemiological surveys and studies. (Circ J 2009; 73: 534-539)
\end{abstract}

Key Words: Body fat mass; Body mass index; Leptin; Lipoprotein; Obesity

$\mathbf{O}$ besity is defined as an excessive accumulation of body fat and has been established as a risk factor for diabetes, hypertension, hyperlipidemia, ischemic heart disease and cerebrovascular disease 1,2 The incidence of obesity in Japan has been increasing every year and is currently reported to be $28.9 \%$ for men and $23.1 \%$ for women, which is lower than in Western countries, but the percentage of obesity in Japanese men of all generations has increased 1.5 -fold over the past 20 years, probably because of the Westernization of lifestyle, particularly the consumption of high-fat food and lack of exercise. Obesity evaluated by body mass index (BMI) in Japanese women older than 60 years has increased, whereas that in women aged in their $20 \mathrm{~s}$ to $50 \mathrm{~s}$ has been disproportionately decreasing.,5 Does this mean that obesity in young Japanese females is decreasing? However, a higher BMI is not

(Received April 30, 2008; revised manuscript received September 28, 2008; accepted October 14, 2008; released online January 15, 2009) Department of Cardiovascular Medicine, Hokkaido University Graduate School of Medicine, Sapporo, *Department of Wellness Planning, Hokusho University, Ebetsu, **Caress Sapporo, Hokko Memorial Clinic, Sapporo, Department of Health Science, Asahikawa Medical College, Asahikawa, ${ }^{\dagger D}$ Department of Health Science, Hokkaido University School of Medicine, Sapporo, $*$ Faculty of Health and Sports Science, Doshisha University, Kyoto and Department of Public Health, Hokkaido University Graduate School of Medicine, Sapporo, Japan

Mailing address: Noriaki Kishimoto, MD, Department of Cardiovascular Medicine, Hokkaido University Graduate School of Medicine, Kita 15, Nishi 7, Kita-ku, Sapporo 060-8638, Japan. E-mail: noriaki-kishimoto@hokkaido.med.or.jp

All rights are reserved to the Japanese Circulation Society. For permissions, please e-mail: cj@j-circ.or.jp always consistent with excess body fat mass (BFM), thus an exact evaluation of the body composition of Japanese female adolescents is needed and was the aim of the present study, which was designed to both determine whether young women with a normal BMI have a normal body fat mass and to assess their lipid profiles, lipoprotein metabolism, insulin resistance and adipocytokine levels.

\section{Methods}

\section{Study Subjects}

The study subjects were 157 healthy women students (mean age, 21 years) from Hokkaido University. Women who had endocrine disease, diabetes mellitus, hyperlipidemia, or hypertension were excluded.

This study conformed to the principles of the Declaration of Helsinki, and written informed consent was given by each subject. The protocol was approved by the Ethics Committee of Hokkaido University Graduate School of Education.

\section{Body Fat Composition}

All subjects were measured for height, weight, waist circumference (at the slimmest part of the waist as viewed from the front) and hip circumference (at the widest part). BMI was calculated as body weight $(\mathrm{kg}) /(\text { height in } \mathrm{m})^{2}$. A normal BMI was defined as $18.5-25 \mathrm{~kg} / \mathrm{m}^{26}$. In addition, BFM, central fat mass (CFM), peripheral fat mass (PFM) and lean body weight (LBW) were measured by dual energy X-ray absorptiometry (DEXA) with a QDR-2000 (Hologic Inc, Boston, MA, USA)? The body fat percentage was calculated as BFM $(\mathrm{kg}) /$ weight $(\mathrm{kg})$ and the range of 
Table 1. Distribution of Study Subjects According to BMI and \%BF

\begin{tabular}{llcc}
\hline \hline $\mathrm{N}=157$ & $\% \mathrm{BF}<22$ & $22 \geq \% \mathrm{BF}<30$ & $\% \mathrm{BF} \geq 30$ \\
\hline $\mathrm{BMI}\left(\mathrm{kg} / \mathrm{m}^{2}\right)<18.5$ & $9(5.7 \%)$ & $7(4.5 \%)$ & $1(0.6 \%)$ \\
$18.5 \geq \mathrm{BMI}<25$ & $0(0 \%)$ & $82(52.2 \%)$ & $31(19.7 \%)$ \\
$\mathrm{BMI} \geq 25$ & $0(0 \%)$ & $21(13.4 \%)$ & $6(3.8 \%)$ \\
\hline
\end{tabular}

BMI, body mass index; \% BF, body fat percentage.

Table 2. Comparison of Physical Measurements Between the Normal and High BFM Groups

\begin{tabular}{lccc}
\hline \hline & Normal BFM $(\mathrm{n}=82)$ & High BFM $(\mathrm{n}=31)$ & P value \\
\hline Age $($ years $)$ & $21.0 \pm 1.7$ & $21.0 \pm 1.8$ & NS \\
Height $(\mathrm{cm})$ & $159.0 \pm 4.9$ & $159.2 \pm 5.1$ & NS \\
Weight $(\mathrm{kg})$ & $51.7 \pm 4.9$ & $53.9 \pm 6.0$ & $<0.05$ \\
BMI $\left(\mathrm{kg} / \mathrm{m}^{2}\right)$ & $20.4 \pm 1.3$ & $21.2 \pm 1.7$ & $<0.05$ \\
Waist circumference $(\mathrm{cm})$ & $65.1 \pm 4.0$ & $68.2 \pm 4.7$ & $<0.01$ \\
Hip circumference $(\mathrm{cm})$ & $92.1 \pm 3.9$ & $94.1 \pm 3.8$ & $<0.05$ \\
Waist-hip ratio & $0.75 \pm 0.05$ & $0.76 \pm 0.05$ & NS \\
\hline
\end{tabular}

Data are mean \pm SD.

BFM, body fat mass; NS, not significant. Other abbreviation see in Table 1.

Table 3. Comparison of Body Fat Composition Between the Normal and High BFM Groups

\begin{tabular}{lccc}
\hline \hline & Normal BFM $(\mathrm{n}=82)$ & High BFM $(\mathrm{n}=31)$ & P value \\
\hline BFM $(\mathrm{kg})$ & $13.6(11.9-14.7)$ & $16.4(15.0-18.8)$ & $<0.001$ \\
$\% \mathrm{BF}(\%)$ & $26.6 \pm 2.3$ & $31.8 \pm 1.7$ & $<0.001$ \\
Lean body weight $(\mathrm{kg})$ & $35.0 \pm 3.4$ & $33.9 \pm 3.6$ & $\mathrm{NS}$ \\
Central fat mass $(\mathrm{kg})$ & $4.0(3.4-4.8)$ & $5.8(4.7-7.0)$ & $<0.001$ \\
Peripheral fat mass $(\mathrm{kg})$ & $8.5(7.7-9.4)$ & $10.2(8.8-10.9)$ & $<0.001$ \\
\hline
\end{tabular}

Data are mean \pm SD or median (interquartile range) for variables with a skewed distribution.

Abbreviations see in Tables 1,2.

Table 4. Comparison of Lipid Levels, Metabolic Profile, and Adipocytokine Levels Between the Normal and High BFM Groups

\begin{tabular}{lccc}
\hline \hline & Normal BFM $(\mathrm{n}=82)$ & High BFM $(\mathrm{n}=31)$ & P value \\
\hline Total cholesterol $(\mathrm{mg} / \mathrm{dl})$ & $181.0 \pm 28.3$ & $189.1 \pm 24.6$ & $\mathrm{NS}$ \\
Triglyceride $(\mathrm{mg} / \mathrm{dl})$ & $55.5(39.8-71.0)$ & $63.0(45.0-87.0)$ & $\mathrm{NS}$ \\
HDL-cholesterol $(\mathrm{mg} / \mathrm{dl})$ & $80.4 \pm 15.1$ & $73.5 \pm 14.5$ & $<0.01$ \\
LDL-cholesterol $(\mathrm{mg} / \mathrm{dl})$ & $90.5(76.0-107.0)$ & $99.0(90.0-123.0)$ & $<0.01$ \\
Free fatty acids $(\mathrm{mmol} / \mathrm{dl})$ & $431.5(213.8-581.0)$ & $446.0(317.0-698.0)$ & $\mathrm{NS}$ \\
CETP $(\mu \mathrm{g} / \mathrm{dl})$ & $2.2 \pm 0.5$ & $2.2 \pm 0.6$ & $\mathrm{NS}$ \\
Fasting blood glucose $(\mathrm{mg} / \mathrm{dl})$ & $83.0 \pm 6.8$ & $82.8 \pm 7.5$ & $\mathrm{NS}$ \\
Fasting plasma insulin level $(\mu \mathrm{U} / \mathrm{ml})$ & $4.0(2.9-5.3)$ & $4.2(3.0-5.4)$ & $\mathrm{NS}$ \\
HOMA-R & $0.8(0.6-1.1)$ & $0.9(0.6-1.1)$ & $\mathrm{NS}$ \\
Leptin $(\mathrm{ng} / \mathrm{ml})$ & $4.6(3.4-8.0)$ & $7.0(5.4-9.4)$ & $<0.05$ \\
Adiponectin $(\mu \mathrm{g} / \mathrm{ml})$ & $11.9 \pm 4.7$ & $10.9 \pm 3.7$ & $\mathrm{NS}$
\end{tabular}

Data are mean \pm SD or median (interquartile range) for variables with a skewed distribution.

HDL, high-density lipoprotein; LDL, low-density lipoprotein; CETP, cholesterol ester transfer protein; HOMA-R, homeostasis model assessment ratio. Other abbreviations see in Table 2.

22-30\% was defined as normal, 9 CFM is the body fat mass in the trunk $(\mathrm{kg})$ and PFM is the body fat in the 4 extremities $(\mathrm{kg})$. Previous studies have confirmed that a significant positive correlation exists between the CFM measured by DEXA and the visceral fat mass measured by magnetic resonance imaging! 10,11 Therefore, in this study, CFM was used as an index of visceral fat mass.

\section{Biochemical Analysis}

Fasting venous samples were collected between the $3^{\text {rd }}$ and $5^{\text {th }}$ days of the menstrual cycle when the level of estrogen is lowest and the levels of total cholesterol (TC), triglycerides (TG), high-density lipoprotein-cholesterol
(HDL-C), free fatty acids (FFA), cholesterol ester transfer protein (CETP), fasting plasma glucose (FPG) and insulin were determined. Low-density lipoprotein-cholesterol (LDL-C) was calculated by Friedewald's formula! ${ }^{2}$ The serum lipids were collectively measured at a clinical laboratory test center accredited by the Lipid Standardization Program of the US Centers for Disease Control and Prevention. The FFA levels were measured using a Labosat NEFA (Shinotest Co, Tokyo, Japan). The level of CETP was determined as previously described ${ }^{13}$ Insulin resistance was assessed using the homeostasis model assessment ratio (HOMA-R) formula; 14 HOMA-R was based on the levels of FPG and fasting plasma insulin: HOMA-R $=(F P G$ 
A

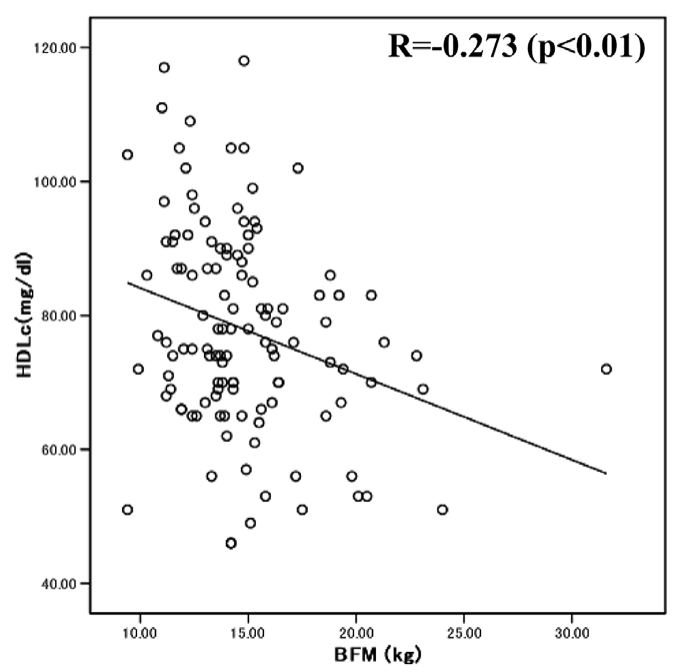

B

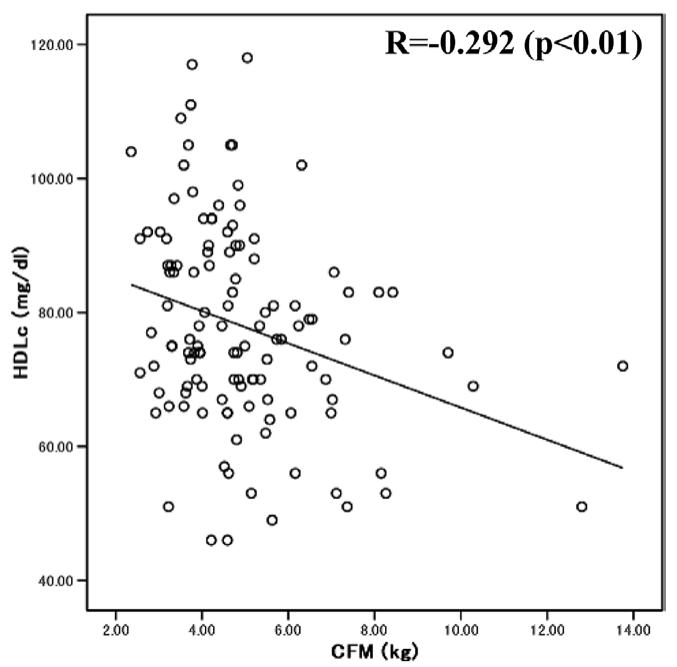

Figure 1. Correlation between the high-density lipoprotein-cholesterol (HDLc) level and body fat mass (BFM, A) or central fat mass (CFM, B).

A

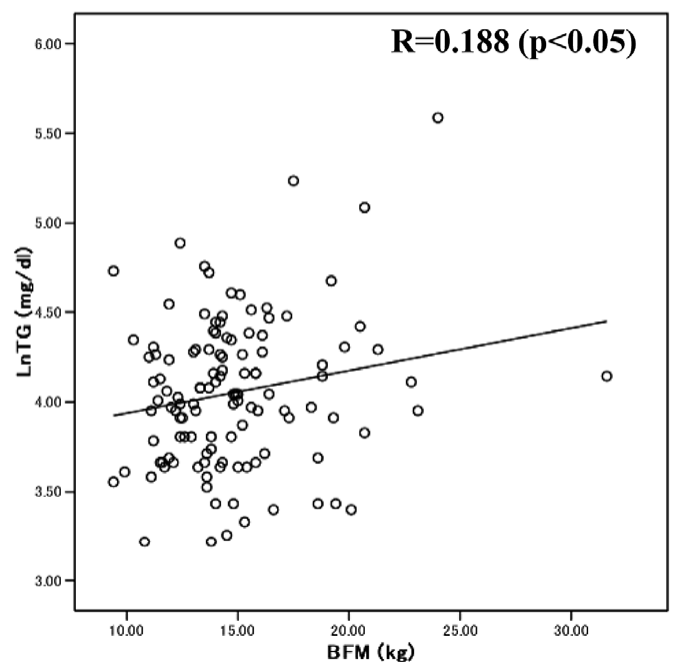

B

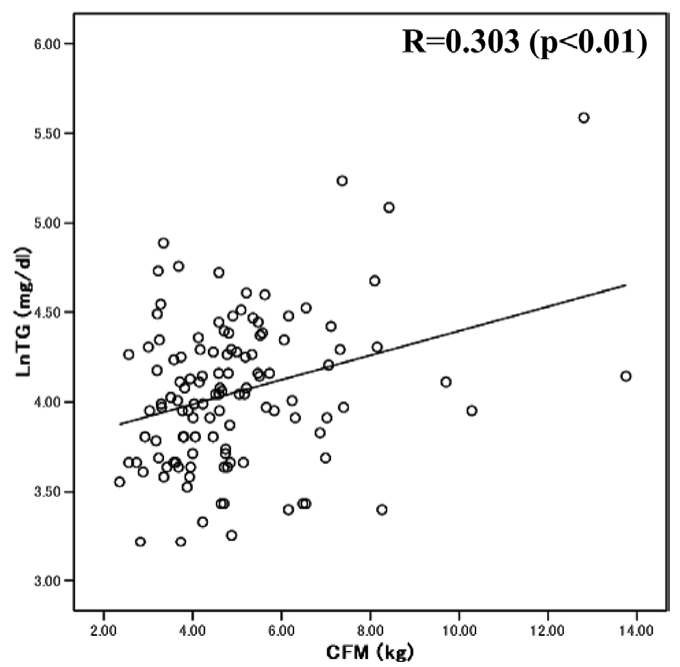

Figure 2. Correlation between the triglyceride level and body fat mass (BFM, A) or central fat mass (CFM, B). LnTG, triglyceride evaluated after conversion to natural logarithms.

level $\times$ fasting insulin level)/405. The levels of FPG and fasting plasma insulin were measured by Clinilog (A\&T Co, Tokyo, Japan) and automated ELISA (TOSO, Tokyo, Japan), respectively. The levels of leptin and adiponectin were determined in serum separated from blood samples by centrifugation and frozen at $-80^{\circ} \mathrm{C}$, using a Human Leptin RIA kit (Cosmic Corporation, Tokyo, Japan) and a Human Adiponectin RIA kit (Linco Research, Inc, St Charles, MO, USA), respectively.

\section{Statistical Analysis}

The clinical and biochemical data of the subjects are shown as the mean \pm SD. Data for parameters that had a non-normal distribution are expressed as the median with interquartile ranges. Differences between the normal body fat composition and the normal BMI-high BFM group were evaluated by Student's t-test. Non-normally distributed parameters (BFM, CFM, PFM, TG, FFA, fasting insulin level, HOMA-
$\mathrm{R}$ and leptin level) were evaluated by Mann-Whitney's test.

The correlation of BFM or CFM with each metabolic parameter was assessed by the Pearson correlation test, and that with non-normally distributed parameters (TG, fasting insulin level, HOMA-R and leptin level) was evaluated after conversion to natural logarithms. All statistical analyses were 2-tailed and performed with SPSS 10.1 (SPSS Inc, Chicago, IL, USA). P values less than 5\% were considered to be statistically significant.

\section{Results}

\section{Anthropometric Measures}

Table 1 shows the BMI distribution of the 157 subjects; only 6 subjects had a high BMI. Although most of the subjects $(130,82.8 \%)$ had $\mathrm{BMI}<25$, a surprising $20.3 \%$ of them showed adiposity $(\mathrm{BFM}>30 \%)$.

The normal BMI-normal BFM group and the normal 
A

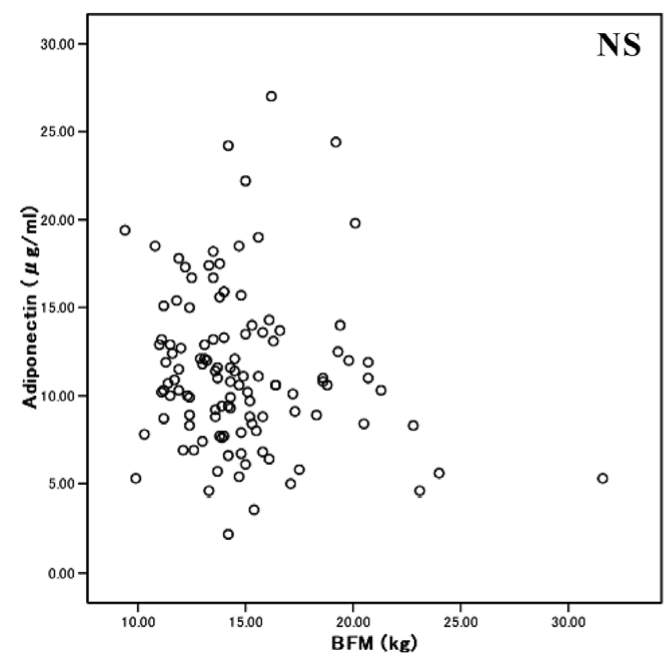

B

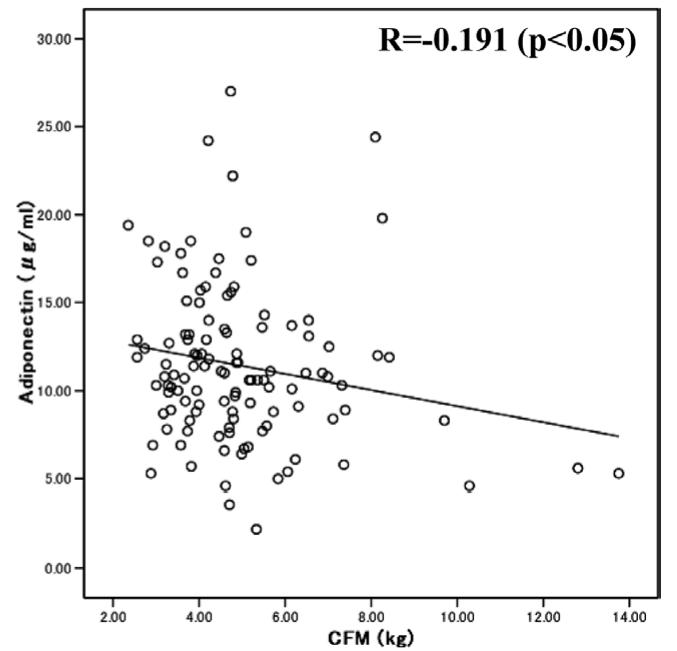

Figure 3. Correlation between the adiponectin level and body fat mass (BFM, A) or central fat mass (CFM, B).

BMI-high BFM group were compared for body fat composition and biochemical parameters. The weight, waist circumference and hip circumference were significantly greater in the normal BMI-high BFM group than in the normal BFM group (Table 2). The BMI of the normal BMI-high BFM group was significantly greater than that of the normal BFM group. The CFM of the normal BMIhigh BFM group were significantly higher than those of the normal BFM group (Table 3). The LBW was slightly lower in the normal BMI-high BFM group than in the normal BFM group, but did not reach statistical significance.

\section{Biochemical Profiles}

In comparison with the normal BFM group, the normal BMI-high BFM group had a significantly higher LDL-C and a lower HDL-C level (Table 4). The levels of TC, TG, FFA, or CETP were comparable between the 2 groups, suggesting that the difference in HDL-C was not related to CEPT. FPG and plasma insulin levels and HOMA-R were also similar between the 2 groups. The level of plasma leptin, but not of plasma adiponectin, was significantly higher in the normal BMI-high BFM group than in the normal BFM group (Table 4).

There was a significant negative correlation between BFM, CFM and HDL-C (Figure 1) and a significant positive correlation between BFM, CFM and TG (Figure 2). No significant correlation was found between BFM and insulin resistance (indicated by HOMA-R). Although BFM showed no significant correlation with the plasma adiponectin level, CFM had a significant positive correlation with the plasma adiponectin level (Figure 3). Both BFM and CFM showed a significant positive correlation with the plasma leptin level. In addition, no significant correlation was observed between CFM and HOMA-R.

\section{Discussion}

\section{Major Findings}

The present study found that approximately $24 \%$ of Japanese female adolescents had an adiposity characterized by a high body fat percentage, and $20 \%$ of the subjects with a normal BMI had excess body fat, lower HDL-C level, higher LDL-C and leptin levels than subjects with a normal BMI and normal body fat. The normal BMI-high BFM group tended to have a lower lean body weight, which suggests that their adiposity was possibly associated with less skeletal muscle mass and might relate to "central obesity" with a high CFM and could be considered to be in a state of "visceral fat accumulation".

Relationship Between Adiposity and Lipid Metabolism

In the present study, HDL-C was significantly lower and LDL-C higher in the normal BMI-high BFM than in the normal BFM group. Moreover, BFM and CFM were significantly correlated with HDL-C, TG and LDL-C. These findings suggest that lipid profiles were associated with changes in BFM. Upper-body obesity has been associated with an abnormal lipid metabolism (hypertriglyceridemia) $)^{15}$ Fujioka et al reported abnormal lipid metabolism (hypercholesterolemia and hypertriglyceridemia) in visceral fat obesity, ${ }^{16}$ and Seon et al described an association of abdominal fat accumulation with low HDL-C and high TG levels! ${ }^{17}$ The lipid metabolism associated with visceral fat accumulation is characterized by elevated serum TG levels associated with reduced HDL-C levels, and an increase in FFA associated with visceral fat accumulation results in an increase in the substrate for the synthesis of very lowdensity lipoproteins; acyl-CoA synthetase activity and microsomal triglyceride transfer protein mRNA levels have been reported as increased in OLETF rats ${ }^{18}$ A significant negative correlation has also been shown between lipoprotein lipase activity and visceral fat accumulation after intravenous injection of heparin. Visceral fat accumulation causes reduced lipoprotein lipase activity and lipoprotein levels, thus resulting in impaired catabolism of lipoproteins, including TG, such as chylomicrons and very lowdensity lipoproteins, thus leading to hypertriglyceridemia ${ }^{19}$

Relationship Between Adiposity and Glucose Metabolism

The present study noted no significant difference in glucose tolerance between the subjects with a normal BMIhigh BFM and those with a normal BFM, and no significant correlation of HOMA-R with BFM or CFM.

A number of clinical studies have shown a relationship 
between diabetes mellitus and obesity or atherosclerotic diseases ${ }^{20,21}$ Obese Caucasian adolescent males and females without metabolic or endocrine disease have significantly lower insulin resistance than normal weight subjects?2 Middle-aged, non-diabetic females with a high HOMA-R have a significantly higher BFM than those with a low HOMA-R 23

Healthy, obese African-American and Caucasian-American adolescents with severe insulin resistance have a higher visceral adiposity than those with mild insulin resistance, despite a similar BMI 24

The lack of any correlation between glucose tolerance and BFM or CFM in the current subjects might be related to their agea and low extent of fat accumulation. The lack of any difference in the glucose tolerance parameters between the groups supports that explanation.

\section{Relationship Between Adiposity and Adipocytokines}

The present study found higher plasma leptin levels in the subjects with a normal BMI-high BFM compared with the normal BFM group. In addition, the leptin levels had a significant positive correlation with BFM and CFM. They were significantly higher in obese young subjects than in the non-obese, and a significant positive correlation existed between the plasma leptin level and BFM ${ }^{25}$ In general, increased leptin levels are considered to result in decreased appetite and food intake, leading to weight loss; however, because simple obesity is associated with decreased leptin sensitivity (ie, increased leptin resistance), such an event does not occur? 26

In the present study, plasma adiponectin levels were within normal ranges and no significant difference was noted between the normal BMI-high BFM and normal BMI-normal BFM groups; however, a weak but significant negative correlation was found between CFM and the plasma adiponectin level, presumably because BFM with a normal BMI was not associated with an excessive accumulation of visceral fat. The plasma adiponectin level has been reported as closely related to body fatness and a key factor in the development of type 2 diabetes, metabolic syndrome and atherosclerosis $27-30$ However, few studies have investigated plasma adiponectin levels in adolescents. Bacha et al reported that adiponectin levels are significantly lower in obese Caucasian male and female youths than in their normal-weight counterparts 22 Similarly, Hara et al noted significantly lower plasma adiponectin levels in obese Japanese male college students than in their nonobese counterparts, and reported that the plasma adiponectin level had a significant negative correlation with $\mathrm{BFM}^{25}$

In conclusion, approximately $24 \%$ of Japanese female adolescents had adiposity characterized by a high body fat percentage, and $20 \%$ of the subjects considered normal by BMI had an excess amount of body fat. The women had relatively higher lipid and leptin levels, probably because of body fat accumulation. These findings may provide important information for future epidemiological surveys and studies, which are needed to investigate the prognosis for this subset of the population.

\section{Acknowledgments}

We thank Mr Brian Quinn for critically reading the manuscript.

\section{References}

1. World Health Organization. The World Health report 2002: Reduc- ing risks, promoting healthy life. Geneva, WHO, 2002.

2. Kobayashi H, Nakamura T, Miyaoka K, Funahashi T, Yamashita S, Matsuzawa Y. Visceral fat accumulation contributes to insulin resistance, small-sized low-density lipoprotein, and progression of coronary artery disease in middle-aged non-obese Japanese men. Jpn Circ J 2001; 65: 193-199.

3. Ministry of Health, Labor and Welfare [Japan]. The survey of national nutrition 2002. Tokyo, the Ministry, 2004.

4. Yoshiike N, Kaneda F, Takimoto H. Epidemiology of obesity and public health strategies for its control in Japan. Asia Pac J Clin Nutr 2002; 11(Suppl 8): S727-S731.

5. Takimoto H, Yoshiike N, Kaneda F, Yoshita K. Increasing "thinness" in young Japanese women. Am J Public Health 2004; 94: $1592-1595$.

6. The Examination Committee, Japan Society for the Study of Obesity. New Criteria for 'Obesity Disease' in Japan. Circ J 2002; 66: 987 992.

7. Michael DJ, Jill AK, Judd ER, Patrick FS. Measurement of abdominal and visceral fat with computed tomography and dual-energy $\mathrm{x}-$ ray absorptiometry. Am J Clin Nutr 1995; 61: 274-278.

8. Frisch RE, McArthur JW. Menstrual cycles: Fatness as a determinant of minimum weight for height necessary for their maintenance or onset. Science 1974; 185: 949-951.

9. McArdle, WD Katch FI, Katch VL. Exercise physiology: Energy, nutrition, and human performance, 3rd edn. Lea \& Febiger, Philadelphia; 1991; 659-662.

10. Kamel EG, McNeill G, Han TS, Avenell A, Davidson L, Tothill P, et al. Measurement of abdominal fat by magnetic resonance imaging, dual-energy X-ray absorptiometry and anthropometry in non-obese men and women. Int J Obes Relat Metab Disord 1999; 23: 686-692.

11. Kamel EG, McNeill G, Wijk CW. Usefulness of anthropometry and DXA in predicting intra-abdominal fat in obese men and women. Obese Res 2000; 8: 36-42.

12. Friedewald WT, Levy RI, Fredrickson DS. Estimation of the concentration of low-density lipoprotein cholesterol in plasma, without use of the preparative ultracentrifuge. Clin Chem 1972; 18: 499-502.

13. Sasai K, Okumura-Noji K, Hibino T, Ikeuchi R, Sakum N, Yokoyama S. Human cholesteryl ester transfer protein measured by enzymelinked immunosorbent assay with two monoclonal antibodies against rabbit cholesterol ester transfer protein: Plasma cholesterol ester transfer protein and lipoproteins among Japanese hypercholesterolemic patients. Clin Chem 1998; 44: 1466-1473.

14. Matthews DR, Hosker JP, Rudenski AS, Naylor BA, Treacher DF, Turner RC. Homeostasis model assessment: Insulin resistance and beta-cell function from fasting plasma glucose and insulin concentrations in man. Diabetologia 1985; 28: 412-419.

15. Kissebah AH, Vydelingum N, Murray R, Hartz AJ, Kalkhoff RK, Adams PW, et al. Relation of body fat distribution to metabolic complications of obesity. J Clin Endocrinol Metab 1982; 54: 254-260.

16. Fujioka S, Matsuzawa Y, Tokunaga K, Tarui S. Contribution of intra-abdominal fat accumulation to the impairment of glucose and lipid metabolism in human obesity. Metabolism 1987; 36: 54-59.

17. Kim SM, Han JH, Park HS. Prevalence of low HDL-cholesterol levels and associated factors among Koreans. Circ J 2006; 70: 820-826.

18. Kuriyama H, Yamashita S, Shimomura I, Funahashi T, Wetterau JR, Matsuzawa Y, et al. Enhanced expression of hepatic acyl-coenzyme A synthetase and microsomal triglyceride transfer protein messenger RNAs in the obese and hypertriglyceridemic rat with visceral fat accumulation. Hepatology 1998; 27: 557-562.

19. Kobayashi J, Tashiro J, Murano S, Morisaki N, Saito Y. Lipoprotein lipase mass and activity in post-heparin plasma from subjects with intra-abdominal visceral fat accumulation. Clin Endocrinol (Oxf) 1998; 48: 515-520.

20. Ban Y, Koba S, Tsunoda F, Yokota Y, Ezumi H, Kondo T, et al. Predominance of small dense low-density lipoproteins and abnormal glucose regulation in patients with acute coronary syndrome. Circ J 2006; 70: 393-401.

21. Shiraishi J, Kohno Y, Sawada T, Nishizawa S, Arihara M, Hadase M, et al; The AMI-Kyoto Multi-Center Risk Study Group. Relation of obesity to acute myocardial infarction in Japanese patients. Circ J 2006; 70: $1525-1530$.

22. Bacha F, Gungor N, Saad R, Arslanian SA. Adiponectin in youth. Diabetes Care 2004; 27: 547-552.

23. Matsubara M, Katayose S, Maruoka S. Decreased plasma adiponectin concentration in nondiabetic women with elevated homeostasis model assessment ratios. Eur J Endocrinol 2003; 148: 343-350.

24. Bacha F, Saad R, Gungor N, Arslanian SA. Are obesity-related metabolic risk factors modulated by the degree of insulin resistance in adolescents? Diabetes Care 2006; 29: 1599-1604.

25. Hara T, Fujiwara H, Shoji T, Mimura T, Nakao H, Fujimoto S. 
Decreased plasma adiponectin levels in young obese males. $J$ Atheroscler Tromb 2003; 10: 234-238.

26. Van Heek M, Compton DS, France CF, Sybertz EJ, Strader CD, Davis HR Jr, et al. Diet-induced obese mice develop peripheral, but not central, resistance to leptin. J Clin Invest 1997; 99: 385-390.

27. On YK, Park HK, Hyon MS, Jeon ES. Serum resistin as a biological marker for coronary artery disease and restenosis in type 2 diabetic patients. Circ J 2007; 71: 868-873.

28. Onat A, Hergenc G, Sari I, Karabulut A, Can G. Elevated LDL-cho- lesterol level predicts diabetes in centrally obese women but not men. Circ J 2007; 71: $1463-1467$.

29. Otsuka F, Sugiyama S, Kojima S, Maruyoshi H, Funahashi T, Sakamoto T, et al. Hypoadiponectinemia is associated with impaired glucose tolerance and coronary artery disease in non-diabetic men. Circ J 2007; 71: $1703-1709$.

30. Hyun YJ, Kim OY, Jang Y, Ha JW, Chae JS, Kim JY, et al. Evaluation of metabolic syndrome risk in Korean premenopausal women. Circ J 2008; 72: 1308-1315. 